\title{
Perception and Importance of Entrepreneurial Leadership in Small and Medium Sized Companies
}

\author{
Muhammad Sajid Saeed (Corresponding Author) \\ Glasgow Caledonian University, UK \\ E-mail: Msaeed14@caledonian.ac.uk
}

Fares Ibrahim

University of Wolverhampton, UK

E-mail: Fares.ibrahim@me.com

Received: May 25, 2016 Accepted: June 8, 2016 Published: June 14, 2016

doi:10.5296/csbm.v3i1.9597ＵRL: http://dx.doi.org/10.5296/csbm.v3i1.9597

\begin{abstract}
The competitive advantage is difficult to obtain in ever-changing business environment. A solution to this problem is entrepreneurial leadership which is vital to attain and uphold competitive advantage in the competitive markets. Hence, this research study was aimed at finding the perception and the importance of entrepreneurial leadership for the UK retail sector particularly the small and medium sized retailers. The small and medium sized retailers registered in the Chamber and Commerce Industry in UK was selected for survey intention. The link to a web-designed questionnaire was sent to business managers and CEOs of these retailers. The responses of survey participants showed a positive perception and the importance of the role of entrepreneurial leadership. However, the UK retail sector needs to work on improving the perception of chaos in order to avoid the high failure rate of small and medium retailers.
\end{abstract}

Keywords: Leadership, Entrepreneurial Leadership, Leadership Competences 


\section{Introduction}

The key aim of this study is to investigate the extent to which entrepreneurial leadership is considered important by small and medium sized retailers in the UK. In this regard, it is important to explore and evaluate the level of perception and importance of entrepreneurial leadership at the managerial level in small and medium sized retailing sector.

For every economy, small and medium size businesses are considered to be important economic contributors. But, these businesses are not simple. They have various issues and challenges which drive their efforts for market survival (Howard, 2013).

In the UK, $80 \%$ of the businesses are in small and medium enterprise category. This $80 \%$ is generating $40 \%$ of the total economic activity. Hence, they are an important base for the UK economy. They create new jobs and reduce unemployment. They reduce income inequalities and provides for economic growth. These businesses are also the most innovative ones and ensure economic empowerment. The employees for these companies constantly learn new things and get chances to be creative and hence stay satisfied with their jobs (Rootman \& Kruger, 2010).

Therefore, the provision of performance opportunities and resources for small, medium and micro businesses can result in overall economic growth and equality in wealth distribution. They stabilise the job market. But, despite these important factors, these businesses are suffering the most in the UK. During the last five years, the failure rate of these businesses was the highest (Rootman \& Kruger, 2010).

The importance of skilled managers and their expertise for every small and medium business was emphasized by Rees \& Porter (2015). They also said that leadership skills of the managers are important for survival of these firms. Just like every other business, small and medium businesses also face the challenge of dealing with small or big changes. They also have to compete at local and also at global levels. Hence, the leadership of small and medium businesses in the UK must also understand the important of revitalisation for growth. They should also focus on being visionary and change driven (Sweeney \& McFarlin, 2001).

Hence, it is clear that the UK retail sector needs to know the importance of change in perception. It must breed entrepreneurial leadership to survive and sustain competitive advantage in the turbulent retail market (Sternberg \& Krauss, 2014).

Keeping in view the above information and the key aim of the paper, the following hypotheses are established:

\section{Hypothesis 1}

H0: The small and medium sized retailers in the UK have a low level of perception about entrepreneurial leadership.

H1: The small and medium sized retailers in the UK have a medium or high level of perception about entrepreneurial leadership. 
Hypothesis 2

H0: The small and medium sized retailers in the UK have a low level of competencies of entrepreneurial leadership.

H1: The small and medium sized retailers in the UK have a medium or high level of competencies of entrepreneurial leadership.

\section{Literature Review}

\subsection{Entrepreneurial Leadership}

Yukl (2006) defined leadership as "the process of influencing others to understand and agree about what needs to be done and how to do it, and the process of facilitating individual and collective efforts to accomplish shared objectives” (p. 8).

Morris \& Jones (1999) defined entrepreneurship as "the process of creating value by bearing together unique combinations of both public and private resources to exploit opportunities” (p. 74).

Dover, Hariharan, \& Cummings (2014) defined Entrepreneurial Leadership as "a process that creates value for organizational stakeholders by bringing together a unique innovation package of resources to respond to a recognized opportunity.” (p. 196).

According to Goossen \& Stevens (2013), entrepreneurial leadership can be defined as that type of leadership which provides for the scenarios where committed followers are gathered to be led by the vision of the leader towards finding new opportunities and utilising them for sustainable success and value for the organisation.

Similarly, entrepreneurial leadership was defined by Yu \& Kwan (2015) as that style of leadership which leads an entrepreneur to take risks, be proactive and be innovative. It also involves organizing and conducting the plans. These aspects are detailed out below:

a. Risk-taking: it is the choice of the leader to face uncertainty and take responsibility for the consequences.

b. Being proactive: providing for innovation during the venture.

c. Being innovative: fostering creative thinking among the team, welcoming new ideas.

d. Organizing: planning how the things will be done and executing these plans.

These definitions summarize two important sides of entrepreneurial leadership which are relevant to this research's objective:

1) Entrepreneurial leadership is a process.

2) It is a style of leadership.

As the name suggests, entrepreneurial leadership is the combination of two theories; entrepreneurship and leadership (Yang, 2008). The need for leadership qualities in entrepreneurs led to the coining of this new phrase (entrepreneurial leadership) among 
researchers (Roomi \& Harrison, 2011).

However, this new field needs further research and development in order to make it worthwhile for synthesis and theoretical considerations (Leitch, McMullan, \& Harrison, 2013). Various empirical studies are now conducted by researchers to investigate the construct of entrepreneurial leadership. According to Cogliser \& Brigham (2004), the research in the field of entrepreneurship and leadership is much similar, especially in terms of its nature and theoretical grounds.

\subsection{Characteristics of Entrepreneurial Leadership}

In the literature, several characteristics of entrepreneurial leaders are identified which include: highly innovation, entrepreneurial style, strong motivation to achieve set goals, high level of enthusiasm, quick reaction to an opportunity, visionary perspective, effectively handling internal and external customers, and opposing hierarchy and bureaucracy (Davies \& Brundrett, 2010; Butts, 2006; Westwood \& Johnson, 2016; Hulsing, 2009).

Nicholson (1998) found that the sample represented differences not only in management styles but also in leadership patterns. The sample of the control group consisted of middle level managers who were not in leadership roles. As the result of this comparison, this study found that entrepreneurial leaders were different from other leaders and managers on the basis of their character. Nicholson (1998) suggested that entrepreneurial leaders are dominant, non-experimental, able to handle stress, conformists and competitive. They are not easily affected by emotions and are focused. Another interpretation of these findings can suggest that such leaders are not influenced by socialisation like other managers. Or it can also be said that they do not conform with the traditional norms of socialisation unless they do not want to be an entrepreneurial leader anymore.

Findings of Cohen (2004) show that entrepreneurial leaders are attracted by the opportunities. They have an eye for the potential product development situations and gaps in the process. Also, they work in a holistic manner which let them take care of every aspect of the process and the company. Due to this reason, they create value in a balanced manner.

A combination of transformational and transactional leadership traits was found in entrepreneurial leaders by Tarabishy et al. (2005). The traits defined by the Visionary Leadership Theory included care, empowerment, communication, trust, confidence and vision. However, all these traits are dependent on the cultural factors of the entrepreneurial leader.

Other than Gupta et al. (2004), a theoretical model was also developed by Van-Zyl \& Mathur-Helm (2007). The purpose was same: developing and assessing the construct of entrepreneurial leadership. Their model was also based on the literature available on leadership and entrepreneurship. They chose reactiveness, innovativeness, risk-taking dimensions of entrepreneurship whereas psycho-emotive, technical and ethical dimensions of leadership. The psycho-emotive dimensions measure the social skills, whereas technical dimensions are related to the way a leader deals with the individual traits of his people. Psycho-emotive defines how much influence a leader has on social dimensions of his 
followers. As the name suggests, ethical dimensions are about the moral values of the leader.

As said before, entrepreneurial leaders are proactive to external opportunities. They have their own creative thinking for these opportunities. Same were the findings of Bateman \& Michael (1999) that entrepreneurial leaders are the creators. They can be seen as the experts in their field. They have the knowledge of the possible problems and their solutions. They know how to create value and sustain competitive advantage. As said above, they have a discovery-oriented approach. This helps them in finding relevant problems and opportunities and designing strategic innovations accordingly. Therefore, they are action-oriented and committed towards the benefit of the company.

\subsection{Entrepreneurial Leadership Competences}

For the need of dynamic business conditions, traditional financial indicators develop suddenly. For this reason, entrepreneurial leaders must always develop new competencies even if the organization is performing well.

According to Bagheri \& Pohie (2011), entrepreneurial leadership comprises of functional competencies and self-competencies. The first set of competencies, which are functional ones, is related to the performance indicators. On the other hand, self-competencies are related to the personal characteristic of the leader (Swiercz \& Lydon, 2002).

In terms of developing the competencies, Swiercz \& Lydon (2002) also agreed that entrepreneurial leaders need to acquire more competencies as the organization develops. They also need to re-visit their own success milestone which the organization has already achieved and challenge it for higher excellence levels. This helps in identifying the warning signs of future threats to the company and continuing innovation. The traditional financial indicators are not sufficient to identify the failure chances as these indicators do not point to the failures in time. These include indicators like return on investment, inventory levels and cash flow scenarios. Rather, some other warning signs are quicker in pointing towards potential future threats. These include coordination issues, short-term crisis planning, undefined jobs, turnover rate and lack of effective management. In conclusion, the two sets of competencies mentioned above are important for those entrepreneurial leaders who have an aim to be on top and are growth oriented (Bagheri, Pihie, \& Krauss, 2012).

\section{Methodology}

\subsection{Research Design}

Research design is formulated by researchers to devise a strategy. It also includes the plan to implement this strategy. According to Cooper \& Schindler (2011), research design includes the plan to collect and analyse data for a research. Similarly, research design has been defined by Creswell (2013) as the framework which lays out the path for a research. Hence, the research design section highlights the strategy of this study together with its plan.

Furthermore, the methods used for primary data collection are also part of a research design. Two such methods are observations and communication. In this particular study, the second method was used (communication). This approach consists of surveys which had been 
adopted for primary data collection in this research.

The survey is a structured method of gathering responses from the sample. It helps a researcher to collect responses in subsets. The benefit of this approach is its comparability. It helps in identifying the similarities and differences among the responses of various subsets of sampling which can be generalised to the whole population after comparing them with statistical tools (Cooper \& Schindler, 2011).

At the end, research design also designates the time dimension for a study. A research can either by longitudinal or cross-sectional in its time approach (Saunders et al., 2009). The definition of longitudinal study shows that it includes the research on the problem for a course of long time. On the other hand, cross-sectional study is conducted in whole at one time and does not involve longer time periods (Creswell, 2013). This study has been conducted at one point of time. Hence it is a cross-sectional study.

\subsection{Research Method}

Research method is defined as those steps or strategies which are undertaken to complete the data collection procedure during a research (Saunders et al., 2009). Researchers use qualitative or quantitative method for this purpose. In this research, the choice of research method was quantitative which helped to investigate the extent to which entrepreneurial leadership is considered important by small and medium sized retailers in the UK. According to Creswell (2013), quantitative method is used to gather data which is of numerical nature. This data can be analysed through statistical tools to find out the numeric relationship. Quantitative data is beneficial, especially when the aim of study is to test existing theories. This study has tested entrepreneurial leadership theories and related concepts. For this purpose, quantitative analyses are applied for gathering data and information from small and medium sized companies in the retail sector of the UK. Moreover, quantitative approach is relevant to investigate and evaluate the entrepreneurial leadership styles. In order to collect the quantitative data, survey method has been used.

\subsection{Population and Sampling}

Sampling is the quantitative technique in which a research chooses some subjects from the whole population. This subject is any individual of the population from whom the response is taken or an object which is observed. Hence, the sample is the unit of population. On the other hand, population includes all the subjects which have been selected for a study. Sample frame includes the list of all possible subjects in a population from which the sample can be chosen (Cooper \& Schindler, 2011, p. 364).

Creswell (2013) has discussed two broad categories of sampling techniques. These are probability sampling (random sampling) and non-probability sampling. In probability sampling, every known subject of the sample frames gets equal chance of being chosen. This category is further divided into simple random sampling, cluster sampling, stratified random sampling, multistage sampling and systematic sampling. On the contrary, non-probability sampling technique does not give equal known chances of selection to each element in the population. This technique is sub-divided into quota sampling, convenience sampling, 
snowball sampling and judgment sampling.

As the current study was focused on small and medium sized retails of the UK, hence the population of the study was all such retail stores in this geographic location. The list of subjects, the sample frame, named all the retailers who were legally registered. The Chamber of Commerce and Industry of UK registers such business. According to the sample frame, 150 stores were affiliated and the survey was conducted among all of these 150 stores.

\subsection{Data Collection}

For the survey, there can be several types of interviews. These include semi-structured interviews, personal interviews and telephonic interviews. Surveys can also be self-administered or online. This includes use of postal mail, fax, email, internet and computer (Olsen, 2011).

In this study, the survey has been conducted using both methods: self-administered and online using the Survey Monkey website. The questionnaire was designed in two parts. The first part included questions related to demographic information of the respondents. The second part consisted of question designed on 5-point Likert scale. These questions were formulated in a way which measured the entrepreneurial leadership style by considering perception and competencies.

Self-administered questionnaires have some benefits as pointed out by Denscombe (2010). These are following: survey is economical; it is easier to conduct; answers are usually standardised. However, there are some disadvantages too. For instance, highly coded questions can irritate the respondents; this coding can result in biased findings; pre-coding does not include a margin for respondent's actual viewpoint; the truthfulness of these responses cannot be measured.

\subsection{Data Analysis}

Data analysis is the procedure in which a researcher analysis the data through statistical tools and reduce its size to an interpretable and manageable size. This helps in finding the relationship between variables and summarizing these findings. The questionnaires generate scaled responses. These are analysed through functional techniques to draw findings. These findings are then correlated with the research hypotheses and objectives to see if the objectives are fulfilled and the hypotheses are true or not (Saunders et al., 2009).

The statistical methods relevantly used in this study included descriptive statistics, and factor analysis.

Cooper \& Schindler (2011) suggest that distribution of responses can be effectively summarized using central tendency, shape and variability of dispersion. Central tendency is usually measured by calculating the mean. Mean is the arithmetic average of a tendency calculated by summing up all the values of responses of a question and then dividing the sum by the number of responses. Dispersion is calculated through variance measurement. This included the sum of squared distances of responses from the mean and then dividing he answer with total number of responses minus by one. 


\section{Macrothink}

Case Studies in Business and Management

ISSN 2333-3324

2016, Vol. 3, No. 1

There are a number of statistical techniques under factor analysis category. These techniques are used by researchers for various purposes, including the scale development, evaluation of tests, categorising the related variables and reducing the number of variables.

\section{Results and Discussion}

\subsection{Demographics Analysis}

From a population of 150, 82 participants filled and submitted the questionnaire which shows nearly $55 \%$ contributions to the study. The male respondents were $84 \%$ of the sample, whereas the rest of $16 \%$ were females. From the entire population, 61 respondents were managers, whereas 21 were CEOs. The majority of respondents had higher education. The postgraduate degree holders were 31 and bachelor degree holders were 15 . Out of the rest of the respondents, diploma holders were 23 . A very low number of only 13 respondents were only high school qualified.

Most of the respondents were highly experienced in their field. 42 out of 82 respondents had an experience of 11 to 15 years. The second highest experience level was more than 15 years, which was selected by 21 respondents, whilst 17 respondents indicated their experience between 5 and 10 years. A majority of responses show that they have an annual turnover of 1 to 5 million. The second majority of 29 respondents agreed to a turnover of 5 to 10 million annually. There were 17 respondents who reported 10 to 15 million turnovers, whereas only 5 selected 0 to 1 million. There were 27 responses for 11 to 20 numbers of employees whereas 20 respondents reported 0 to 5 employees. Similarly, 18 and 17 respondents selected 6 to 10 employees and 21 to 50 employees respectively. This shows that most of the respondents in the sample have 11 to 20 employees.

\subsection{Descriptive Statistics}

\subsubsection{Leadership Style-Perception Statistics}

The result of analysis of questions in leadership style section is shown in Table 1. According to this table, most of the respondents selected to agree with the questions. However, the strongly disagreed response was also given to three questions which were F7, F11 and F15. Similarly, strong agreed statements included F9 and F14.

The highest standard deviation was found for questions F3, F7, F11, F15 and F19. This means that the answers to these questions varied greatly as compared to other questions in this section. The higher standard deviation means greater dispersion of responses. They are spread across the scale. The scale consisted of points from strongly disagree to strongly agree. A majority of Agree (3) responses was clustered on question F18 for this section. 
Table 1. Descriptive of perception scale-leadership style

\begin{tabular}{|l|l|l|l|l|l|l|l|}
\hline Sr. \# & N & Mean & Median & Mode & S.D. & Min. & Max. \\
\hline F1 & 82 & 3.06 & 3 & 3 & 0.674 & 1 & 4 \\
\hline F2 & 82 & 3.14 & 3 & 3 & 0.635 & 2 & 4 \\
\hline F3 & 82 & 2.54 & 3 & 3 & 1.072 & 1 & 4 \\
\hline F4 & 82 & 3.10 & 3 & 3 & 0.610 & 2 & 4 \\
\hline F5 & 82 & 2.77 & 3 & 3 & 0.812 & 2 & 4 \\
\hline F6 & 82 & 3.32 & 3 & 3 & 0.536 & 2 & 4 \\
\hline F7 & 82 & 1.46 & 1 & 1 & 1.042 & 1 & 4 \\
\hline F8 & 82 & 2.21 & 3 & 3 & 0.623 & 2 & 4 \\
\hline F9 & 82 & 3.39 & 3 & 4 & 0.580 & 2 & 4 \\
\hline F10 & 82 & 3.40 & 3 & 3 & 0.509 & 2 & 4 \\
\hline F11 & 82 & 1.85 & 1 & 3 & 1.222 & 1 & 4 \\
\hline F12 & 82 & 2.89 & 3 & 3 & 0.581 & 2 & 4 \\
\hline F13 & 82 & 3.10 & 3 & 3 & 0.679 & 2 & 4 \\
\hline F14 & 82 & 3.32 & 3 & 4 & 0.623 & 2 & 4 \\
\hline F15 & 82 & 1.92 & 2 & 1 & 1.260 & 1 & 4 \\
\hline F16 & 82 & 3.15 & 3 & 3 & 0.597 & 1 & 4 \\
\hline F17 & 82 & 3.09 & 2 & 3 & 0.637 & 1 & 4 \\
\hline F18 & 82 & 3.24 & 3 & 3 & 0.477 & 2 & 4 \\
\hline F19 & 82 & 2.60 & 3 & 3 & 1.023 & 1 & 4 \\
\hline F20 & 82 & 3.07 & 3 & 3 & 0.545 & 2 & 4 \\
\hline
\end{tabular}

\subsubsection{Leadership Style-Importance Statistics}

In this section, leadership style scale was paired with a leadership importance scale. The pairing of two scales allows a researcher to give one scale for two different dimensions of the concept. In this case, the two dimensions of the leadership were its perceived importance and its perceived style which were paired together for rating on the same questions. 
Table 2. Descriptive of importance scale-leadership style

\begin{tabular}{|l|l|l|l|l|l|l|l|}
\hline Sr. \# & N & Mean & Median & Mode & S.D. & Min. & Max. \\
\hline F1 & 82 & 2.94 & 3 & 3 & 0.701 & 1 & 4 \\
\hline F2 & 82 & 3.19 & 3 & 3 & 0.655 & 2 & 4 \\
\hline F3 & 82 & 2.26 & 2 & 3 & 0.866 & 1 & 4 \\
\hline F4 & 82 & 3.11 & 3 & 3 & 0.667 & 2 & 4 \\
\hline F5 & 82 & 2.83 & 3 & 3 & 0.779 & 1 & 4 \\
\hline F6 & 82 & 3.39 & 3 & 3 & 0.565 & 2 & 4 \\
\hline F7 & 82 & 1.58 & 2 & 2 & 1.062 & 1 & 4 \\
\hline F8 & 82 & 3.28 & 3 & 3 & 0.595 & 3 & 4 \\
\hline F9 & 82 & 3.24 & 3 & 4 & 0.702 & 2 & 4 \\
\hline F10 & 82 & 3.38 & 3 & 4 & 0.550 & 2 & 4 \\
\hline F11 & 82 & 1.78 & 2 & 2 & 1.130 & 1 & 4 \\
\hline F12 & 82 & 2.72 & 3 & 3 & 0.706 & 2 & 4 \\
\hline F13 & 82 & 3.02 & 3 & 3 & 0.765 & 2 & 4 \\
\hline F14 & 82 & 3.28 & 3 & 3 & 0.564 & 2 & 4 \\
\hline F15 & 82 & 1.80 & 2 & 2 & 1.172 & 1 & 4 \\
\hline F16 & 82 & 3.00 & 3 & 3 & 0.639 & 2 & 4 \\
\hline F17 & 82 & 3.08 & 3 & 3 & 0.549 & 2 & 4 \\
\hline F18 & 82 & 3.21 & 3 & 3 & 0.538 & 3 & 4 \\
\hline F19 & 82 & 2.58 & 3 & 3 & 0.820 & 1 & 4 \\
\hline F20 & 82 & 3.04 & 3 & 3 & 0.588 & 2 & 4 \\
\hline
\end{tabular}

The results of this paired analysis are given in Table 2. The spread of responses shows that the section was well responded. The most selected answer among the responses was "extremely important”. Likewise, the majority of respondents selected "very important". The scale of "low important" was chosen by most respondents for questions F7, F11 and F15. The choice of "extremely important (4)" was selected mostly for questions F9 and F10. The highest standard deviation was seen in responses to F7, F11 and F15. The answers to these questions were spread across the whole scale. It can be seen from the Table that F10 had the most inclination towards the answer "extremely important" and similarly "very important" was chosen the most in response to F17.

\subsection{Factor Analysis}

For factor analysis, the 20 items listed in section B were analysed for suitability first. These items were related to leadership style. First of all, the component matrix for this screening showed that there was no negative scoring for these items. Therefore, scores were not reversed.

After this, the correlation matrix was conducted. This came out with correlation coefficients of 0.3 and above. This figure was important. This showed that the data can undergo factor analysis. Similarly, the Kaiser-Meyer-Olkin value of 0.765 was found in this data. The 
recommended value for this test is 0.6 which is much lower (Hinton, 2004). Also, the results of Bartlett's test of Sphericity confirmed that suitability of data for factor analysis. In this test, the data reached the statistical significance for factor analysis (0.000).

Table 3 lists down the communalities for this data. The extraction shows the variance of each item in section B. According to Pallant (2007), the value of communality is below 0.3 means that the particular is not suitable for the set of items. In this table, this unsuitability was observed in F1 and F18.

Table 3. Leadership style (communalities)

\begin{tabular}{|l|l|}
\hline Item No. & Extraction \\
\hline F1 & 0.291 \\
\hline F2 & 0.416 \\
\hline F3 & 0.464 \\
\hline F4 & 0.366 \\
\hline F5 & 0.455 \\
\hline F6 & 0.760 \\
\hline F7 & 0.562 \\
\hline F8 & 0.528 \\
\hline F9 & 0.481 \\
\hline F10 & 0.623 \\
\hline F11 & 0.763 \\
\hline F12 & 0.370 \\
\hline F13 & 0.566 \\
\hline F14 & 0.599 \\
\hline F15 & 0.660 \\
\hline F16 & 0.498 \\
\hline F17 & 0.551 \\
\hline F18 & 0.278 \\
\hline F19 & 0.661 \\
\hline F20 & 0.501 \\
\hline
\end{tabular}

Table 4 shows the results of total variance matrices. This matrix helped in determining the number of variables to be sustained. There were five factors which had the Eigenvalues of more than 1 for Principle Axis factoring. These factors were related to 28.2\%, 14.2\%, 8.4\%, $7.0 \%$ and $6.3 \%$ of the total variance. This means that these five factors contributed a $64.1 \%$ of the variance. 


\section{Macrothink}

Case Studies in Business and Management

ISSN 2333-3324

2016, Vol. 3, No. 1

Table 4. Leadership style—-total variance explained

\begin{tabular}{|c|c|c|c|c|c|c|c|c|c|}
\hline \multirow[b]{2}{*}{ 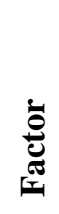 } & \multicolumn{3}{|c|}{$\begin{array}{l}\text { Initial } \\
\text { Eigenvalues }\end{array}$} & \multicolumn{3}{|c|}{$\begin{array}{l}\text { Extraction Sums of Squared } \\
\text { Loadings }\end{array}$} & \multicolumn{3}{|c|}{$\begin{array}{l}\text { Rotation Sums of Squared } \\
\text { Loadings }\end{array}$} \\
\hline & Total & $\begin{array}{l}\text { \% of } \\
\text { Variance }\end{array}$ & Cumulative \% & Total & $\begin{array}{l}\text { \% of } \\
\text { Variance }\end{array}$ & Cumulative \% & Total & $\begin{array}{l}\text { \% of } \\
\text { Variance }\end{array}$ & Cumulative \% \\
\hline 1 & 5.371 & 28.275 & 28.275 & 4.902 & 25.805 & 25.805 & 2.736 & 14.406 & 14.406 \\
\hline 2 & 2.693 & 14.167 & 42.442 & 2.318 & 12.196 & 38.001 & 2.544 & 13.384 & 27.79 \\
\hline 3 & 1.610 & 8.289 & 50.731 & 1.099 & 5.788 & 43.789 & 1.736 & 9.14 & 36.93 \\
\hline 4 & 1.339 & 7.054 & 57.785 & 0.849 & 4.474 & 48.263 & 1.495 & 7.865 & 44.795 \\
\hline 5 & 1.183 & 6.33 & 64.115 & 0.739 & 3.885 & 52.148 & 1.396 & 7.352 & 52.147 \\
\hline 6 & 0.961 & 5.131 & 69.246 & & & & & & \\
\hline 7 & 0.793 & 4.176 & 73.422 & & & & & & \\
\hline 8 & 0.721 & 3.783 & 77.205 & & & & & & \\
\hline 9 & 0.622 & 3.28 & 80.485 & & & & & & \\
\hline 10 & 0.586 & 3.082 & 83.567 & & & & & & \\
\hline 11 & 0.559 & 2.945 & 86.512 & & & & & & \\
\hline 12 & 0.488 & 2.562 & 89.074 & & & & & & \\
\hline 13 & 0.418 & 2.203 & 91.277 & & & & & & \\
\hline 14 & 0.386 & 2.025 & 93.302 & & & & & & \\
\hline 15 & 0.357 & 1.883 & 95.185 & & & & & & \\
\hline 16 & 0.317 & 1.665 & 96.85 & & & & & & \\
\hline 17 & 0.239 & 1.265 & 98.115 & & & & & & \\
\hline 18 & 0.214 & 1.125 & 99.24 & & & & & & \\
\hline 19 & 0.144 & 0.76 & 100 & & & & & & \\
\hline
\end{tabular}

At the end, these five factors for section B were listed down together with their link to the items as given by rotated factor matrix. These lists are given below:

Table 5. Factor 1 -developing relationships

\begin{tabular}{|l|l|l|}
\hline Sr. \# & Statement & Loading \\
\hline F8 & Do you support innovative ideas produced from effective team relationships? & 0.648 \\
\hline F10 & Do you consider communication as an important tool for change? & 0.660 \\
\hline F12 & Do you believe that individuals occasionally identify? & 0.456 \\
\hline F14 & Do you consider communication as a lifeblood of an organisation? & 0.420 \\
\hline F16 & Do you think, employees can maximize their potential by developing relationships? & 0.640 \\
\hline F19 & Do you use the chaotic situation as an opportunity to improve business operations? & 0.687 \\
\hline
\end{tabular}


Table 6. Factor 2-chaos

\begin{tabular}{|l|l|l|}
\hline Sr. \# & Statement & Loading \\
\hline F3 & Chaos can be used to make necessary changes as transformation procedure & 0.632 \\
\hline F7 & Do you believe that chaos is important to develop new ideas in business? & 0.694 \\
\hline F11 & Do you think chaos brings opportunities for the business? & 0.838 \\
\hline & $\begin{array}{l}\text { Do you consider chaos as a necessary procedure that helps to identify weaknesses in the } \\
\text { current system? }\end{array}$ & 0.805 \\
\hline
\end{tabular}

Table 7. Factor 3-vision

\begin{tabular}{|l|l|l|}
\hline Sr.\# & Statement & Loading \\
\hline F1 & The vision of business is an unseen power that affects employee behaviour & 0.532 \\
\hline F13 & Do you think that your company's vision motivates you and employees? & 0.600 \\
\hline F17 & Do you think that the vision of a business shows its ambition, goal and capacity? & 0.703 \\
\hline F18 & $\begin{array}{l}\text { Do you think that communicating with every employee under your supervision leads to } \\
\text { greater adaptability? }\end{array}$ & 0.368 \\
\hline
\end{tabular}

Table 8. Factor 4-communication

\begin{tabular}{|l|l|l|}
\hline Sr. \# & Statement & Loading \\
\hline F2 & The necessary task-based information is shared with subordinates in your company & 0.591 \\
\hline F6 & Do you believe that communicating with employees can lessen resistance to change? & 0.836 \\
\hline
\end{tabular}

Table 9. Factor 5-teamwork

\begin{tabular}{|l|l|l|}
\hline Sr. \# & Statement & Loading \\
\hline F4 & Building relationships within teams is always encouraged in your company & 0.428 \\
\hline F5 & Do you believe that team effort and interaction can lead business vision? & 0.634 \\
\hline F20 & $\begin{array}{l}\text { Do you think that as a manager, you motivate employee relationships in order to build } \\
\text { organisational commitment? }\end{array}$ & 0.638 \\
\hline
\end{tabular}

\section{Discussion}

As found in the literature, the entrepreneurial leadership helps a business survive and is equally important in the retail sector (Roomi \& Harrison, 2011). This finding was supported by the responses which showed that $77 \%$ of respondents agreed to the importance of entrepreneurial leadership. The analysis also showed a high mean rating. This means that respondents are aware of the importance of entrepreneurial leadership for sustained competitive advantage as pointed out by Darling et al. (2007).

Furthermore, the mean score of $78 \%$ shows a belief of respondents for possessing the 
entrepreneurial leadership skills. The same results were indicated in the literature. It was indicated by Tarabishy et al. (2005) that retail sector has considerable entrepreneurial leadership. However, the contradiction to literature was seen when the responses did not agree with the literature view of vision being the most important skill of an entrepreneurial leader (Fernald et al., 2005). Most responses said that informing and communicating are the most important ones.

During literature review, it was found that vision enactment (Fernald et al., 2005) teamwork and leading change (Chen, 2007, p. 246) are the key roles of an entrepreneurial leader. Literature also gave four dimensions of the construct of entrepreneurial leaders. These were vision, informing and communicating, accepting chaos and relationship building. Vision dimension shows the acceptability for a new vision among the participants. This dimension was given an 83\% majority vote in responses. Informing and communicating shows how much free is the flow of information within these companies. This also scored very high which was $86 \%$. The synergy and integration of relations in a company are indicated by relationship building dimension. This too scored a high value of $82 \%$. The dimension of accepting chaos depicts the ability of respondents to react positively to situations of chaos. This dimension showed a very low percentage of only $62 \%$. This means that participants might not be willing to deal with chaos and not agreeing to the importance of chaos for organisational growth. According to Tarabishy et al. (2005), entrepreneurial leadership skills of a business make it equipped to handle changing market conditions. But, the situation of lower acceptability of chaos means that entrepreneurial leadership might not be helpful for more hostile market conditions as pointed out by Mithas et al. (2013).

A rating of $77 \%$ was given to the importance of entrepreneurial leadership by the respondents of this study. Among the dimensions of the construct, the importance of vision was agreed by $82 \%$ of these managers and leaders. Likewise, informs and communicates dimension also scored very highly rated of $86 \%$, the least important dimension was found to be chaos with only $61 \%$ rating. This shows that chaos is not considered by these leaders as the important contributor to the organisational revitalisation.

The findings of the responses showed an important trend. The means of entrepreneurial leadership and its importance were nearly the same. They also matched by the means of the dimensions of entrepreneurial leadership. This suggests that perceptions of entrepreneurial leadership style and its importance are considerably correlated. Also, the importance of chaos and the acceptance of chaos also showed almost similar results of $61 \%$ and $62 \%$ respectively. This interlinked outcome confirmed the indication given by Yang (2008) that chaos is not necessarily important for deriving change through entrepreneurial leadership.

\section{Conclusion and Recommendations}

The competitive advantage is difficult to sustain in ever-changing business markets. A solution to this problem is entrepreneurial leadership. However, the concept of entrepreneurial leadership is also complex. Nevertheless, researchers have agreed that vision enactment, team enactment and deriving innovation and change are the three major roles of an entrepreneurial leader. Based on the available literature on Entrepreneurial Leadership, it 
can be concluded that it is extremely necessary for existence of enterprises in the retail sector. Entrepreneurial Leadership in the retail sector is effective in developed countries like UK. However, it varies on the basis of environment changes and becomes hostile.

This empirical research was aimed at finding the perception and the importance of entrepreneurial leadership in the UK retail sector and particularly the small and medium retailers in the UK. The responses of the managers and leaders of these businesses in the UK retail market showed a positive perception about the role of entrepreneurial leaders. These business managers and CEOs thought of entrepreneurial leadership as equally important as the changing market conditions. The qualification differences of the respondents do not seem to affect their responses. All of them thought the same about the relationship between entrepreneurial leadership and retail sector dynamism. Similarly, the number of years of job experience also did not affect the responses. The answers were necessarily the same among those with less than 20 years of experience and those with more than 20 years of experience. Also, the responses were essentially the same regardless of turnover rate of the respondent's firm. It can be concluded that the perception of individuals about the entrepreneurial leadership and their perception of its importance was the same regardless of many differing factors.

An important indication was found in literature about the chaos being an important dimension for organisational growth and revitalisation. However, the respondents do not seem to agree to that. Hence, the population seems to be in need to be given more information and awareness on the importance of chaos in driving change.

The respondents were found to be highly educated and experienced. Their responses showed a higher agreement to vision, communication and relationships. This means that they possess a higher level of knowledge, skill and expertise. Such leaders should be made a necessary component of small and medium sized business by government. The government can enforce the presence of such a leader to all those business which get start-up funding from government. This can help prevent the rate of failure among small and medium firms.

During the successful fulfilment of research objectives, the null hypotheses of the study were rejected and it can be said that the small and medium sized retailers in the UK has a medium or high level of perception and competencies of entrepreneurial leadership.

\section{References}

Bagheri, A., \& Pihie, Z. A. (2011). Student Entrepreneurial Leaders: Challenges and Competencies of Leading University Entrepreneurship Programs. International Journal of Business and Social Science, 2(2), 133-144.

Bagheri, A., Pihie, Z. A., \& Krauss, S. E. (2012). Entrepreneurial leadership competencies among Malaysian university student entrepreneurial leaders. Asia Pacific Journal of Education, 33(4), 493-508. http://dx.doi.org/10.1080/02188791.2013.822789

Bateman, T., \& Michael, C. J. (1999). Proactive Behavior: Meaning, Impact, Recommendations. Business Horizons, 42(3), May/Jun99, p. 63. 
http://dx.doi.org/10.1016/S0007-6813(99)80023-8

Butts, B. G. (2006). The Entrepreneurial Leader as Change Agent: Developing Innovative Churches. Asbury. Theological Seminary.

Chen, M. H. (2007). Entrepreneurial leadership and new ventures: creativity in entrepreneurial teams. Creativity and Innovation Management, 16(3), 239-249. http://dx.doi.org/10.1111/j.1467-8691.2007.00439.x

Cogliser, C. C., \& Brigham, K. H. (2004). The intersection of leadership and entrepreneurship: mutual lessons to be learned. The Leadership Quarterly, 15(6), 771-799. http://dx.doi.org/10.1016/j.leaqua.2004.09.004

Cohen, A. R. (2004). Building a company of leaders. Leader to Leader, 34, 16-20. http://dx.doi.org/10.1002/ltl.96

Cooper, D. R., \& Schindler, P. S. (2011). Business research methods (11th ed.). New York: McGraw-Hill.

Creswell, J. W. (2009). Research Design: Qualitative, Quantitative, and Mixed Methods Approaches. Thousand Oaks: SAGE Publications.

Darling, J. R., Keeffe, M. J., \& Ross, J. K. (2007). Entrepreneurial leadership strategies and values: keys to operational excellence. Journal of Small Business and Entrepreneurship, 20(1), 41. http://dx.doi.org/10.1080/08276331.2007.10593385

Davies, B., \& Brundrett, M. (2010). Developing Successful Leadership. Berlin: Springer Science \& Business Media. http://dx.doi.org/10.1007/978-90-481-9106-2

Denscombe, M. (2010). The good research guide for small-scale social research projects (4th ed.). Berkshire: McGraw Hill.

Dover, P. A., Hariharan, S., \& Cummings, M. G. (2014). Leadership and Governance. Proceedings of the 2nd International Conference on Management, ICMLG 2014, Academic Conferences Limited.

Fernald, L. W., Solomon, G. T., \& Tarabishy, A. (2005). A new paradigm: entrepreneurial leadership. Southern Business Review, 30(2), 1-10.

Goossen, R. J., \& Stevens, R. P. (2013). Entrepreneurial Leadership: Finding Your Calling, Making a Difference. Downers Grove, IL: InterVarsity Press.

Gupta, V., MacMillan, I. C., \& Surie, G. (2004). Entrepreneurial leadership: developing and measuring a cross-cultural construct. Journal of Business Venturing, 19(2), 241-260. http://dx.doi.org/10.1016/S0883-9026(03)00040-5

Hinton, P. R. (2004). SPSS Explained. London: Psychology Press.

Howard, E. (2013). The Changing Face of Retailing. London, New York: Routledge.

Hulsing, R. D. (2009). Leadership and Entrepreneurial Success: The Relationship of 
Leadership Factors and Economically Successful Entrepreneurial Endeavors. Discover the world's research.

Jones, O., \& Crompton, H. (2009). Enterprise logic and small firms: a model of authentic entrepreneurial leadership. Journal of Strategy and Management, 2(4), 329-351. http://dx.doi.org/10.1108/17554250911003836

Leitch, C. M., McMullan, C., \& Harrison, R. T. (2013). The Development of Entrepreneurial Leadership: The Role of Human, Social and Institutional Capital. British Journal of Management, 24(3), 347-366. http://dx.doi.org/10.1111/j.1467-8551.2011.00808.x

Mithas, S., Tafti, A., \& Mitchell, W. (2013). How a firm's competitive environment and digital strategic posture influence digital business strategy. MIS Quarterly, 37(2), 511-536.

Nicholson, N. (1998). Personality and entrepreneurial leadership: a study of the heads of the UK's most successful independent companies. European Management Journal, 16(5), 529-539. http://dx.doi.org/10.1016/S0263-2373(98)00030-9

Olsen, W. (2011). Data Collection: Key Debates and Methods in Social Research. Thousand Oaks: SAGE Publications.

Pallant, J. (2007). SPSS survival manual: a step by step guide to data analysis using SPSS for Windows (3rd Ed.). Berkshire: Open University Press.

Rees, W. D., \& Porter, C. (2015). Skills of Management and Leadership: Managing People in Organisations. London: Palgrave Macmillan.

Roomi, M. A., \& Harrison, P. (2011). Entrepreneurial leadership: What is it and how should it be taught? International Review of Entrepreneurship, 9(3), 1-44.

Rootman, C., \& Kruger, J. (2010). Adapting SMME business functions during economic turmoil. ActaCommercii, 10, 107-119.

Saunders, M., Lewis, P., \& Thornhill, A. (2009). Research methods for business students (5th ed.). Harlow: Pearson Education.

Sternberg, R., \& Krauss, G. (2014). Handbook of Research on Entrepreneurship and Creativity. Cheltenham, Camberley, Northampton, \& Massachusetts: Edward Elgar Publishing.

Sweeney, P. D., \& McFarlin, D. B. (2001). Organizational behavior: solutions for management. London: McGraw-Hill Irwin.

Tarabishy, A., Solomon, G., Fernald, L. W., \& Sashkin, M. (2005). The entrepreneurial leader's impact on the organization's performance in dynamic markets. The Journal of Private Equity, 8(4), 20-29. http://dx.doi.org/10.3905/jpe.2005.580519

Van Zyl, H., \& Mathur-Helm, B. (2007). Exploring a conceptual model, based on the combined effects of entrepreneurial leadership, market orientation and relationship marketing orientation on South Africa's small tourism business performance. South African Journal of 
Business Management, 38(2), 17-24.

Westwood, R., \& Johnson, T. (2016). Five Characteristics of a Successful Entrepreneur. San Clemente, CA: Sourced Media Books, LLC.

Yang, C. W. (2008). The Relationships Among Leadership Styles, Entrepreneurial Orientation, and Business Performance. Managing Global Transitions, 6(3), 257-275.

Yu, F. L., \& Kwan, D. S. (2015). Chinese Entrepreneurship: An Austrian Economics Perspective. London, New York: Routledge.

Yukl, G. (2006). Leadership in organizations (6th ed.). Upper Saddle River, NJ: Pearson-Prentice Hall.

\section{Copyright Disclaimer}

Copyright for this article is retained by the author(s), with first publication rights granted to the journal.

This is an open-access article distributed under the terms and conditions of the Creative Commons Attribution license (http://creativecommons.org/licenses/by/3.0/). 